\title{
Mycobacterial Cell Wall-DNA Complex
}

National Cancer Institute

\section{Source}

National Cancer Institute. Mycobacterial Cell Wall-DNA Complex. NCI Thesaurus. Code C64765.

A proprietary preparation of mycobacterial DNA oligonucleotides embedded in mycobacterial cell wall fragments derived from cultures of Mycobacterium phlei, with potential immunomodulatory and antineoplastic activities. DNA oligonucleotides in the mycobacterial cell wall-DNA complex (MCC) are capable of inducing apoptosis by increasing BAX protein levels, releasing cytochrome $\mathrm{C}$ from mitochondria, and activating caspase-3 and -7. This leads to the cleavage of poly (ADP-ribose) polymerase and the release of nuclear matrix proteins (NuMA). In addition to its pro-apoptotic effect, MCC activates monocytes and macrophages to produce various cytokines, including interleukin 6 (IL-6), IL-8, IL-12, IL-18, and tumor necrosis factor alpha (TNF-a). This leads to an activation of natural killer cells and cytotoxic T lymphocytes and to interferon gamma (INF-g) synthesis, thereby attaining an anti-angiogenic effect. 